Tropical Journal of Pharmaceutical Research October 2011; 10 (5): 603-609

(C) Pharmacotherapy Group,

Faculty of Pharmacy, University of Benin

Benin City, 300001 Nigeria.

All rights reserved.

Available online at http://www.tjpr.org

Research Article

http://dx.doi.org/10.4314/tjpr.v10i5.9

\title{
Effect of Dietary Intake of Fermented Seeds of Parkia biglobosa (Jacq) Benth (African Locust Bean) on Hypertension in Bogou and Goumou-kope Areas of Togo
}

\begin{abstract}
K Ognatan ${ }^{1}$, K. Adi ${ }^{1,3}$, C Lamboni ${ }^{1}$, J-M Damorou ${ }^{2}$, KA Aklikokou ${ }^{3}$, M Gbeassor $^{3}$ and J-C Guilland ${ }^{4}$

${ }^{1}$ Laboratoire de Biochimie/Nutrition, Université de Lomé, Faculté des Sciences, ${ }^{2}$ Service de Cardiologie du Centre Hospitalier Universitaire, Faculté de Médecine, ${ }^{3}$ Laboratoire de Physiologie-Pharmacologie, Faculté des Sciences, Université de Lomé, BP : 1515 Lome, Togo, ${ }^{4}$ Practicien hospitalier, Unité Neuromédiateurs et Vitamines, Laboratoire de Physiologie de la Faculté de Médecine, Université de Bourgogne, BP $87900 B^{d}$ Jeanne-d'Arc, 21033 Dijon-Cedex, France.
\end{abstract}

\begin{abstract}
Purpose: To identify the possible effect of the consumption of fermented seeds of Parkia biglobosa (Jack) Benth, Mimosaceae (African locust bean) by humans on the prevention of hypertension.

Methods: Two types of populations in Togo were identified and compared: one type was in a region (Bogou) where the condiment (Parkia biglobosa seeds) is highly consumed and the other people do not eat it at all (Goumou-kope). Anthropometrical, clinical and biochemical analyses were investigated in both target groups.

Results: Significantly decreased blood pressure and heart beat were detected in the group of people living in Bogou's region when compared to the non-consumption group of Goumou-kope $(p<0.001)$. Magnesium level was significantly increased in the Bogou group compared to that in the second group $(p<0.0001)$. Lower levels of low density lipoprotein-cholesterol (91 $\pm 36 \mathrm{vs}$. $110 \pm 44 \mathrm{mg} / \mathrm{dL}, p=0.01)$, triglycerides (111 \pm 6 vs. $129 \pm 6 \mathrm{mg} / \mathrm{dL}, p=0.028)$, and higher levels of high density lipoproteincholesterol (63 \pm 2 vs. $48 \pm 3 \mathrm{mg} / \mathrm{dL}, p<0.001$ ) were observed in subjects who regularly consummed $P$. biglobosa fermented seeds. Furthermore, plasma glucose concentration was significantly lower in Bogou group than in Goumou-kope (68 \pm 16 vs. $76 \pm 15 \mathrm{mg} / \mathrm{dL}$ ( $p<0.001)$.

Conclusion: The results of the present study demonstrate that fermented seeds of Parkia biglobosa exert an anti-hypertension effect.
\end{abstract}

Keywords: Blood minerals, Plasma lipids, Antihypertensive, Parkia biglobosa seeds 


\section{INTRODUCTION}

Cardiovascular diseases (CVD) are disorders of heart and blood vessels that affect many people around the world and hypertension is a major modifiable risk factor for CVD and mortality [1]. The relationship between hypertension and CVD is continuous and independent of other risk factors [2]. The control of blood pressure has been shown to be effective in reducing CVD and mortality [3]. Hypertension is now a common condition in both developed and developing countries. It is characterized by blood pressure which remains abnormally high - systolic blood pressure $\geq 140 \mathrm{mmHg}$ and diastolic pressure $\geq 90 \mathrm{mmHg}$ [4]. Increased blood pressure in adulthood is associated with large reductions in life expectancy [5].

Blood pressure may be modulated by the plasma level of some biochemical parameters including minerals (such as magnesium, potassium, calcium) and lipid profile (including total cholesterol (TC), high density lipoprotein (HDL)-cholesterol, low density lipoprotein (LDL)-cholesterol and triglycerides). Dietary approach is considered to better manage blood pressure $[6,7]$

The fermented seeds of Parkia biglobosa, which belongs to the family, Mimosaceae, are used in some West Africa countries, including Benin, Mali, Senegal and Togo, to season traditional soups $[8,9]$. The use of $P$. biglobosa in the traditional treatment of hypertension is on the increase [8]. The fermented seeds, used as a soup seasoning, have been identified as a source of essential amino acids and fatty acids for infant nutrition [10].

Although antihypertensive activities of $P$. biglobosa in animals have been documented, there is very little knowledge of its effect in humans [8]. Therefore, the present study was designed to investigate the antihypertensive effects of $P$. biglobosa in humans by measuring levels of mineral ions $\left(\mathrm{Ca}^{++}, \mathrm{K}^{+}\right.$,
$\mathrm{Na}^{+}, \mathrm{Mg}^{2+}$ and $\mathrm{Cl}^{-}$) as well as total cholesterol, triglycerides, glucose and LDLcholesterol, in order to assess the probable effect of the consumption of fermented seeds of $P$. biglobosa on these parameters which are linked to hypertension.

\section{EXPERIMENTAL}

\section{Study population}

Two hundred subjects of both sexes, aged between 40 and 80 years, from two different areas of Togo were initially recruited for this study but only those in the age bracket of 40 - 50 years actually participated. They were divided into two groups. Group 1 comprised subjects $(n=100)$ from the northern area of Togo (Bogou) who had a long-term habit (more than five years) of consumption of condiments $(100 \mathrm{~g} / \mathrm{day})$ containing fermented seeds of $P$. biglobosa, while Group $2(n=100)$ from the southern region of Togo (Goumou-kope) had never consumed this condiment.

Enrollees underwent two kinds of examinations - anthropometrical and biochemical - as described below. All the participants gave their written informed consent and the international guidelines for biomedical research involving human subject was strictly adhered to [11], and approval for the study was obtained from the bioethics committee of the Ministry of Health of Togo.

\section{Clinical assessment}

Blood pressure was measured twice on the right and left arms of each participant in a sitting position, with the aid of a sphygmomanometer HEINE (Germany). Participants with mean systolic pressure $\geq 140 \mathrm{mmHg}$ and mean diastolic blood pressure $\geq 90 \mathrm{mmHg}$ were classified as having hypertension. Heart rate was also measured using sphygmomanometer. 
Information about prior CVD and eating habits was obtained using a questionnaire.

\section{Evaluation of anthropometric parameters}

Body weight was measured using a digital scale (Seca, model 762, Germany). Subjects were weighed in light clothing and without shoes. Standing height was measured without shoes to the nearest $0.5 \mathrm{~cm}$ with a commercial stadiometer (PMA, model PM5000BS, France), with the shoulders in relaxed position and arms hanging freely as described by Lohman [12]. Body mass index (BMI) was calculated by dividing weight $(\mathrm{kg})$ by the square of height squared $\left(\mathrm{m}^{2}\right)$.

\section{Assessment of biochemical parameters}

Venous blood samples were obtained in vacutest heparinated tubes (Italy) from each subject for biochemical analysis, following a $12 \mathrm{~h}$ overnight fast, and stored in tanks containing dry ice and then centrifuged for plasma separation at $3000 \mathrm{rpm}$ for $15 \mathrm{~min}$ at room temperature. The plasma was then transferred into plastic Eppendorf tubes and frozen at $-18^{\circ} \mathrm{C}$ pending analysis.

\section{Minerals}

Plasma potassium, sodium, chloride, magnesium and calcium were determined using commercial diagnostic kits (Cypress Diagnostics Laboratory) on an automated spectrophotometer (Clima Plus, Ral.SA), following the kit manufacturers' guide in each case. For potassium, the absorbance was read at $500 \mathrm{~nm}$ and the turbidity obtained is proportional to potassium concentration. Sodium assay utilized a principle based on a modification of the method described by Maruna and Trinders using Avecom kits [13]. Absorbance was read at $550 \mathrm{~nm}$. Chloride level was determined based on its absorbance at $480 \mathrm{~nm}$ while magnesium concentration was determined from the absorbance at $520 \mathrm{~nm}$. Calcium concentration evaluated based on its absorbance at $570 \mathrm{~nm}$.

\section{Assessment of lipids and glucose}

Total cholesterol (TC) and triglycerides (TG) from commercial kits (Cypress Diagnostics) were quantified using enzymatic methods. For TG estimation, a working reagent was prepared by first mixing buffer (Reagent 1 buffer) and enzymes (Reagent 2) from Cypress Diagnostics. The mixture was incubated for $5 \mathrm{~min}$ and the absorbance of the sample and standard were read against the blank at $505 \mathrm{~nm}$. Cholesterol concentration was determined using two reagents: buffer with phenol and the enzyme complex consisting of cholesterol esterase (CHE), cholesterol oxidase (CHO) and peroxidase (POD). High density lipoprotein cholesterol (HDL-C) in the supernatant was measured at $500 \mathrm{~nm}$ spectrophotometrically after precipitation of very low density lipoprotein (VLDL) and low density lipoprotein (LDL) by phosphotungstate, in the presence of magnesium ions. LDL-C concentration was calculated using Friedewald equation (Eq 1) [14].

$\mathrm{LDL}=\mathrm{TC}-(\mathrm{HDL}+\mathrm{TG} / 5)$

Glucose concentration in plasma was determined by a colorimetric method using glucose oxidase (GOD). Absorbance of sample and standard solutions were read at $505 \mathrm{~nm}$ (Cypress Diagnostics) against the blank.

\section{Statistical analysis}

Data are expressed as mean \pm standard error of the mean $(n=100)$. Statistical significance was evaluated by Student's $t$ test using Systat 5.0 and SPSS 12 for Windows. Differences were considered significant at $p<$ $0.05,<0.001$ or $<0.001$, depending on the parameter.

\section{RESULTS}

There was no significant difference $(p<0.05)$ between the age of Goumou-kope and Bogou groups. Similarly, the BMI data of the two 
groups were not significantly different $(p<$ 0.05).

\section{Cardiovascular data}

Blood pressure (BP), either systolic blood pressure (SBP) or diastolic blood pressure (DBP) was significantly different $(p<0.001)$ between the two groups with the values lower for the Bogou group (Fig 1 and 2). This difference was evident for either arm of the body. Heart rate was significantly lower in Bogou people than in Goumou-kope population $(p<0.0001)$.

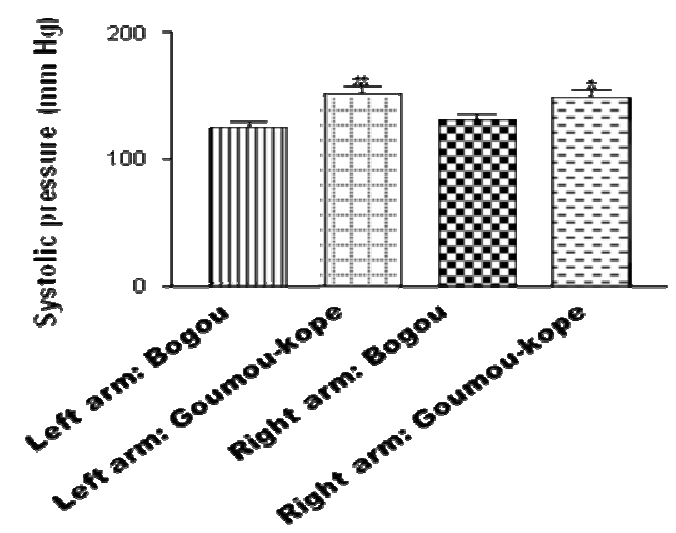

Fig 1: Systolic blood pressure of the subjects Systolic blood pressure histogram of Bogou compared to that of Goumou-kope

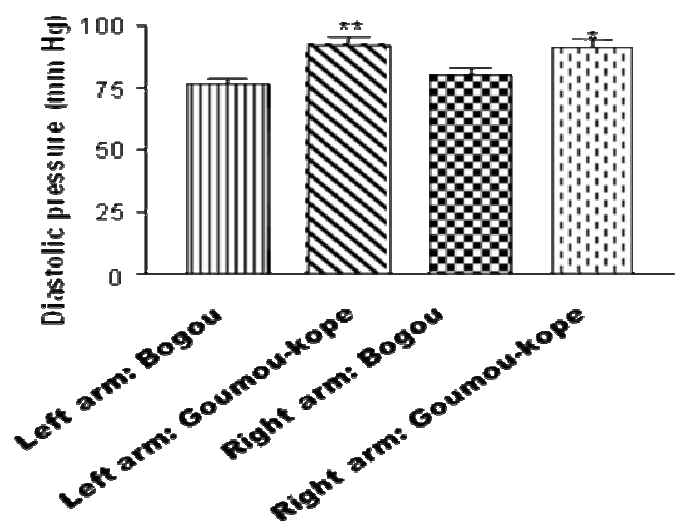

Fig 2: Diastolic blood pressure of the subjects Diastolic blood pressure histogram of Bogou compared to that of Goumou-kope

\section{Biochemical data}

Table 1 shows plasma mineral ion levels for subjects for the study. Bogou people were distinguished by their lower potassium level $(p<0.001)$, sodium and calcium levels $(p<$ 0.0001 ) but elevated magnesium concentration $(p<0.0001)$ than in Goumou-kope group.

Table 1: Some plasma mineral ion content for Bogou and Goumou-kope (mean \pm SE, $n=100$ )

\begin{tabular}{lll}
\hline Parameter & \multicolumn{2}{c}{ Groups } \\
\cline { 2 - 3 } & Bogou & Kouumou-kope \\
\hline Magnesium, mg/l & $110.7 \pm 1.6^{\star *}$ & $20.1 \pm 0.4$ \\
Calcium, mg/l & $85.9 \pm 2.4^{* *}$ & $110.0 \pm 1.6$ \\
Sodium, mmol/l & $143.1 \pm 1.2^{* *}$ & $149.2 \pm 0.8$ \\
Potassium, mmol// & $3.9 \pm 0.1^{*}$ & $4.5 \pm 0.1$ \\
Chloride, $\mathrm{mmol} / \mathrm{l}$ & $99.26 \pm 1.38^{*}$ & $102.93 \pm 0.69$ \\
${ }^{*} p<0.01 ;{ }^{* *} p<0.001$ &
\end{tabular}

Table 2 shows the plasma lipid data for the two groups of people. Bogou group showed lower levels of LDL-C (90.9 \pm 35.7 vs. 110.3 $\pm 44.8 \mathrm{mg} / \mathrm{dL}, p=0.01)$, TG (110.7 \pm 5.93 vs. $129.1 \pm 5.8 \mathrm{mg} / \mathrm{dL}, p=0.028)$ than Goumoukope group. However, HDL-C concentration was higher in Bogou's group (62.6 \pm 1.6 vs. $48.3 \pm 2.7 \mathrm{mg} / \mathrm{dL}, p<0.001$ ) than in Goumou-kope group. Consequently, lower TC/HDL-C ratio $(2.95 \pm 0.13$ vs. $4.47 \pm 0.27$ $\mathrm{mg} / \mathrm{dL}, p<0.001)$ and LDL-C/HDL-C ratio $(1.57 \pm 0.11$ vs. $2.91 \pm 0.24 \mathrm{mg} / \mathrm{dL}, p<$ 0.001 ) were observed in Bogou group than in Goumou-kope. Nevertheless, TC (175.7 \pm 3.2 vs. $180.8 \pm 3.3 \mathrm{mg} / \mathrm{dL}, p=0.275)$ was not significantly different in the two groups.

Plasma glucose concentration in Bogou's enrollees was significantly lower than that in Goumou-kope's group (67.80 \pm 16.3 vs. $76.40 \pm 15.3 \mathrm{mg} / \mathrm{dL}, \mathrm{P}<0.001)$.

\section{DISCUSSION}

Our findings in human subjects support the results of Assane et al who demonstrated that consumption of fermented seeds of $P$. biglobosa by rabbits had a mitigating effect on hypertension [8].

Trop J Pharm Res, October 2011;10(5):606 
Table 2: Comparison of lipid and glucose levels in Bogou and Goumou-kope groups (mean \pm SE, $n=100$ )

\begin{tabular}{lccc}
\hline Plasma parameter & \multicolumn{2}{c}{ Grous } & $p$-value \\
\cline { 2 - 3 } & Bogou & Goumou-kope & \\
Total cholesterol, mg/dL & $175.7 \pm 3.2$ & $180.8 \pm 3.3$ & 0.275 \\
HDL cholesterol, mg/dL & $62.6 \pm 1.6$ & $48.3 \pm 2.7$ & $<0.001$ \\
Triglicerides, mg/dL & $110.7 \pm 5.9$ & $129.1 \pm 5.8$ & 0.028 \\
LDL cholesterol, $\mathrm{mg} / \mathrm{dL}$ & $90.9 \pm 35.7$ & $110.3 \pm 44.8$ & 0.01 \\
Total $: \mathrm{HDL}$ cholesterol, $\mathrm{mg} / \mathrm{dL}$ & $2.95 \pm 0.13$ & $4.47 \pm 0.27$ & $<0.001$ \\
LDL $: \mathrm{HDL}$ cholesterol, $\mathrm{mg} / \mathrm{dL}$ & $1.57 \pm 0.11$ & $2.91 \pm 0.24$ & $<0.001$ \\
Glucose, $\mathrm{mg} / \mathrm{dL}$ & $67.8 \pm 16.3$ & $76.4 \pm 15.3$ & - \\
\hline
\end{tabular}

In the present study, both groups were similar in age and had identical BMI values that were not significantly different, suggesting that differences in blood pressure and plasma parameters were neither due to age nor BMI. The lower diastolic and systolic blood pressure values in Bogou group are reinforced by the lower heart rate values. Although a previous study showed that BMI is linked to hypertension [15], our study indicates that differences in the values of these clinical parameters between the two subject groups were not influenced by BMI.

The differences in the cardiovascular data are probably attributable to the type and quantity of diet regularly consumed by the two groups of people. People living in Bogou area often consume fermented seeds of $P$. biglobosa in their diets, whereas those in Goumou-kope do not. Earlier studies found a similar hypotensive effect in rats and in rabbits that consumed these fermented seeds[8,16,]. Interestingly, this plant has been identified as a source of cardiac glycosides, tannins, and alkaloids; these constituents may therefore play a role in lowering BP in Bogou people [17-19].

This study also showed the link between high plasma level of magnesium and lower heart and blood pressure in the subjects who usually eat the condiment, thus further accounting for lower BP in the Bogou group. High magnesium content of the condiment has previously been reported [10]. Magnesium has been shown to be beneficial for lowering the risk of cardiovascular disease and its deficiency in blood is known to be involved in hypertension [20]. Other reports suggest increased consumption of major food sources of magnesium, such as whole grains, nut, and green leafy vegetables as a means of lowering BP [21].

The plasma sodium level was significantly higher in Goumou-kope group, a factor that might have contributed to the higher blood pressure observed in this population. Significantly, calcium, potassium and chloride levels were also lower in this group. Calcium and potassium intake are known to protect against hypertension [22]. The relatively high levels of these ions may be related to the long-term consumption of seafoods by Goumou-kope population since the town is situated by the Atlantic ocean.

The levels of deleterious lipids was lower in Bogou group which consume the fermented seeds of the plant. Lower LDL-C concentration has also been observed in Bogou population by Griel et al [23]. The combined effect of decreased LDL-C and increased HDL-C usually leads to decreased LDL-C/HDL-C ratio which would favour better cardiovascular health. Another work also found that the aqueous extract of the plant significantly increased and decreased serum levels of HDL-C and LDL-C, respectively, in rats, resulting in increased HDL-C/LDL-C ratio [24]. Although TC concentration was not significantly lower in Bogou subjects, $\mathrm{TC} / \mathrm{HDL}-\mathrm{C}$ ratio was significantly lower in these subjects than in the Goumou-kope group. 
TG is known to be a predictor of hypertension risk [25]; this parameter was lower in the Bogou population. Importantly, the beneficial effect of PB fermented seeds with respect to this parameter has been shown in a previous study [24]. In the peripheral vascular system, endothelial cells rely on lipoproteins for the transfer of neutral sterols at this site. Although free cholesterol is transferred to HDL particles through the functioning of a designated HDL receptor, lecithin cholesterol acyl transferase (LCAT) serves to maintain the concentration toward the HDL core and preserve the hydrophobic nature that facilitates the transfer. Esterification of cholesterol produces cholesterol ester (CE), which is concentrated in HDL core, and may be transferred by cholesterol ester transfer protein (CETP) in the plasma compartment to apo-B containing lipoproteins in exchange for TG. Increased CETP activity would suggest an enrichment of apo-B lipoproteins in plasma, while simultaneously decreasing HDL-C, and has generally been considered pro-atherogenic [26]. This probably explains why the presence of fermented seeds of $P$. biglobosa in diet may lead to a reduction in the risk of developing heart diseases since a high HDL-C/LDL-C ratio has been shown to be beneficial and is indicative of a lower risk of cardiovascular disease [27].

In addition to having a possible antihyperlipidaemic effect, it is possible that the fermented seeds of the plant may also provide antidiabetic activity. Although our findings appear to indicate a lower level of glyceamia in Bogou people than in Goumoukope people, the difference was not statistically different $(p<0.05)$. However, an earlier study demonstrated the antidiabetic activity of the plant extract in rats [24].

\section{CONCLUSION}

Our results show that the hypotensive effect of the fermented seeds of Parkia biglobosa, previously observed in rats, is also likely to be manifest in humans. This is particularly so since some critical plasma parameters such as TG, HDL, magnesium and glucose levels all seem to favour lower blood pressure.

\section{ACKNOWLEDGMENT}

This work was partially supported by the University of Lomé, Lome, Togo. The authors are grateful to the study participants for their invaluable contribution.

\section{REFERENCES}

1. Yusuf S, Hawken S, Dans T. INTERHEART Study Investigators. Effect of potentially modifiable risk factors associated with myocardial infarction in 52 countries: a case control study. Lancet 2004; 364: 937- 952.

2. Lewington S, Clarke R, Qizilbash N. Age-specific relevance of usual blood pressure to vascular mortality. Lancet 2002; 360: 1903-1913

3. Franklin SS, Jacobs MJ, Wong ND. Predominance of isolate systolic hypertension among middleaged and elderly US hypertensives: analysis based on National Health and Nutrition Examination Survey (NHANES). Hypertens 2001; 37: 869-874

4. Chobanian AV, Bakris GL, Black HR. The Seventh Report of the Joint National Committee on Prevention, Detection, Evaluation and Treatment of high Blood Pressure: the JNC 7 report. J Am Med Assoc 2003; 289: 25602572.

5. Franco $\mathrm{OH}$, Peeters $A$, Bonneux $L$, de Laet $C$. Blood Pressure in Adulthood and Life Expectancy with Cardiovascular Disease in Men and Women. Hypertens 2005; 46 (2): 280-286.

6. Ard JD, Coffman CJ, Lin PH, Svetkey LP. One-year follow-up study of blood pressure and dietary patterns in dietary approaches to stop hypertension (DASH)-sodium participants. Am J Hypertens 2004; 17: 1156-1162

7 Dauchet L, Kesse-Guyot E, Czernichow S, Bertrais $S$, Estaquio $C$, Péneau $S$, Vergnaud AC, ChatYung $S$, castetbon $K$, Deschamps $V$, Brindel $P$, Hercberg $S$. Detary patterns and blood pressure change over 5-year follow-up in the SU.VI.MAX cohort. Am J Clin Nutr 2007; 85: 1650-1656

8 Assane M, Baba-moussa R, Bassene E, Sere A. Etude de l'action antihypertensive des graines de Parkia biglobosa(JACQ). Benth chez le rat. Dakar-Méd 1993; 38: 49-54

9. Ajaiyeoba EO. Phytochemical and antibacterial properties of Parkia biglobosa and Parkia bicolor leaf extracts. Afr J Biomed Res 2002; 5: 125-129.

10 Lamboni C, Monkpoh K, Konlani S, Doh A. Caractéristiques alimentaires $d u$ «Tonou», 


\section{Ognatan et al}

condiment à base de soja ou de graines de néré. Med Nut 1999; 2: 50-65.

11. International Ethical Guidelines for Biomedical Research Involving Human Subjects, 2002. Available from: http://www.fhi.org/training $/$ fr/retc/pdf

12. Lohman T, Roche A, Mastorell R. Anthropometric standardization reference manual. Champaign, IL: Human Kinetics, 1991

13. AVECON Six Sigma. LiquIMAX Sodium ( $\mathrm{Na}+)$ Potassium K+) Optimized (Colorimetric method). [Accessed 2011 March 7] Available from: http://aveconhealthcare.com/pdfs/liqui max/SODIUM\%20(Na+)\%20 POTASSIUM $\% 0(K+) \% 20($ OPTIMIZED)\%20COLORIMATRI C.pdf (7/03/2011)

14. Sassolas A. Bilan lipidique: nouvelles recommendations, nouvelles nomenclatures. 2006. [Acessed 2011 March 7] Available from : http://www.probioqual.com/exEPU.pdf du

15. Jee SH, Sull WJ, Park J, Body-Mass Index and Mortality in Korean Men and Women. $N$ Engl $J$ Med 2006; 355: 779-787

16 Mori TA. Omega-3 Fatty Acids and Hypertension in Humans. Clin Exp Pharmacol Physiol 2006; 33: $842-846$

17. Odetola AA, Akinloye O, Egunjobi C, Adekunle WA, Ayoola AO. Possible antidiabetic and antihyperlipidaemic effect of fermented Parkia biglobosa (Jacq) extractct in alloxan-induced diabetic rats. Clin exp Pharmacol Physiol 2006; 33: 808- 812

18 Millogo-Kone $H$, Guissou IP, Nacoulma O, Traore AS. Comparative study of leaf and stem bark extract of Parkia biglobosa against enterobacter. Afr J trad CAM 2008; 3: 238_243

19 Ajaiyeoba EO. Phytochemical and antibacterial properties of Parkia biglobosa and Parkia bicolor leaf extract. Afr J Biomed Res 2002; 5 : 125-129
20. Gums JG. Magnesium in cardiovascular and other disorders. Am J Health-System Pharmacy 200;. 61: 1569-1576

21. Lopez-Ridaura $R$, Willett WC, Rimm EB. Magnesium intake and risk of type 2 diabetes in men and women. Diabetes Care 2004; 27: 134-140.

22. Zemel MB. Calcium Modulation of Hypertension and Obesity: Mechanisms and Implications. J Am Coll Nutr 2001; 20: 428-435

23. Griel A, Cao Y, Bagshaw D. A macadamia nut-rich diet reduces total and $L D L$-cholesterol in mildly hypercholesterolemic men and women. J Nutr 2008; 138: 761-767.

24. Odetola AA, Akinloye O, Egunjobi C, Adekunle WA, Ayoola AO. Possible Antidiabetic and Antihyperlipidaemic Effect of Fermented Parkia biglobosa (Jacq) extract in Alloxan- Induced Diabetic Rats. Clin Exp Pharmacol 2006; 33: 808-812.

25. Allen RR, Carson LA, Kwik-Uribe C, Evans E, Erdman JW. Daily consumption of a dark chocolate containing flavanols and added sterol esters affects cardiovascular risk factors in normotensive population with elevated cholesterol. J Nutr 2008; 138: 725731.

26. Greene CM, Zern TL, Wood RJ, Shrestha $S$, Fernandez ML. Maintenance of the $L D L$ cholesterol/HDL cholesterol ratio in an elderly population given a dietary cholesterol challenge. J Nutr 2005; 135: 2793-2798.

27. Perona JS, Covas MI, Fito M, Cabello-Moruno R, Aros F, Corella D, Ros E, Garcia M, Estruch R, Martinez-Gonzalez MA, Ruiz-Gutierrez V. Reduction in systemic and VLDL triacylglycerol concentration after a 3-month Mediterraneanstyle diet in high-cardiovascular-risk subjects. J Nutr Biochem 2010; 9: 892-898 